\title{
Possibilidades e limitações da abordagem de questão sociocientífica na alfabetização científica e tecnológica de estudantes
}

\author{
Possibilities and limitations of addressing a socioscientific issue in the \\ scientific and technological literacy of students
}

Robson Almeida Monteiro de Farias Licenciado em química Universidade Federal Rural de Pernambuco - UFRPE.

Recife, Pernambuco - Brasil. rob.almeidadefarias@gmail.com

Ruth do Nascimento Firme Doutora em Educação

Universidade Federal Rural de Pernambuco - UFRPE. Recife, Pernambuco - Brasil. ruth.nascimento@ufrpe.br

\begin{abstract}
Resumo: Neste estudo, tivemos como objetivos identificar os níveis de Alfabetização Científica e Tecnológica (ACT) expressados por estudantes no desenvolvimento de uma intervenção didática com a abordagem de Questão Sociocientífica (QSC) e analisar possibilidades e limitações da intervenção didática desenvolvida na emergência dos níveis de ACT identificados. Neste sentido, conduzimos uma pesquisa qualitativa com a participação de trinta estudantes do Ensino Médio de uma escola pública estadual e seguimos três etapas metodológicas: planejamento da intervenção didática a partir da abordagem de QSC; desenvolvimento da intervenção didática planejada; e coleta e análise dos dados. Em nossos resultados, identificamos os três níveis de ACT nos estudantes: prática, cívica e cultural. Como possibilidades para a emergência desses níveis de ACT, destacamos a compreensão de implicações econômicas, sociais, éticas e políticas envolvidas no derramamento de óleo no litoral do nordeste e, como limitações, a ausência de discussão sobre valores, interesses e opiniões pessoais dos estudantes.
\end{abstract}

Palavras chave: abordagem de questão sociocientífica; alfabetização científica e tecnológica.

\begin{abstract}
In this study, we aimed to identify the levels of Scientific and Technological Literacy (STL) expressed by students in the development of a didactic intervention with the Socioscientific Issues (SSI) approach and to analyze possibilities and limitations of the didactic intervention developed in the emergence of the identified STL levels. In this sense, we conducted a qualitative research with the participation of thirty high school students from a public school, and we followed three methodological steps: planning of didactic intervention based on the SSI approach; development of planned didactic intervention; and data collection and analysis. In our results, we identified three levels of STL in students: practice, civic and cultural. As possibilities for the emergence of STL levels, we highlight the understanding of economic, social, ethical and political implications involved in the oil spill off the coast of the northeast, and as limitations, the lack of discussion about the students' values, interests and personal opinions.
\end{abstract}

Key-words: socioscientific issues approach; scientific and technological literacy.

Cite como

(ABNT NBR 6023:2018)

FARIAS, Robson Almeida Monteiro de; FIRME, Ruth do Nascimento. Possibilidades e limitações da abordagem de questão sociocientífica na alfabetização científica e tecnológica de estudantes. Dialogia, São Paulo, n. 39, p. 1-16, e19718, set./dez. 2021. Disponível em: https://doi.org/10.5585/39.2021.19718.

American Psychological Association (APA)

Farias, R. A. M. de., Firme, R. do. N. (2021, set./dez.) Possibilidades e limitações da abordagem de questão sociocientífica na alfabetização científica e tecnológica de estudantes. Dialogia, São Paulo, 39, p. 1-16, e19718. https://doi.org/10.5585/39.2021.19718. 


\section{Introdução}

Neste estudo, tivemos como objetivos identificar os níveis de Alfabetização Científica e Tecnológica ${ }^{1}$ (ACT) expressos por estudantes no desenvolvimento de uma intervenção didática com abordagem da Questão Sociocientífica (QSC), a qual intitulamos "Desastres ambientais: derramamento de óleo no litoral do nordeste", e analisar possibilidades e limitações da intervenção didática desenvolvida na emergência dos níveis de ACT identificados.

O ensino em ciências passa por (re)estruturações ao tempo que se busca acompanhar a evolução cultural (CONRADO; NUNES-NETO, 2018; ZEIDLER; NICHOLS, 2009). À medida que se constrói história, novos conceitos científicos e tecnologias são desenvolvidos. Neste caminho, o ensino de ciências não é um processo que ocorre à margem das mudanças sociais e, portanto, precisa considerar aspectos envolvidos nessas mudanças, como, por exemplo, as discussões políticas, econômicas, éticas, culturais e ambientais.

Diversos pesquisadores da área de ensino de ciências (ALMEIDA; GUIMARÃES, 2019; BOCHECO, 2011; GENOVESE, C.; GENOVESE, L.; CARVALHO, 2019; KOLSTO, 2004; PÉREZ, 2012; ZEIDLER; HERMAN; SADLER, 2019) e documentos oficiais nacionais (BRASIL, 1996, 2018) defendem que a atual educação científica busca formar sujeitos críticos, (auto)reflexivos e emancipados; sujeitos esses que sejam capazes de questionar, participar, opinar e atuar em debates que envolvem problemáticas presentes no desenvolvimento histórico e cultural da sociedade relativas às atividades científicas e tecnológicas.

No Brasil, por exemplo, a Lei de Diretrizes e Base da educação nacional (BRASIL, 1996) defende, como uma das finalidades do ensino médio, “o aprimoramento do educando como pessoa humana, incluindo a formação ética e o desenvolvimento da autonomia intelectual e do pensamento crítico" (BRASIL, 1996, p. 24). Ademais, a Base Nacional Comum Curricular de 2018 (BRASIL, 2018) descreve dez competências gerais da educação básica e, dentre outras, destacamos a primeira: "valorizar e utilizar os conhecimentos historicamente construídos sobre o mundo físico, social, cultural e digital para entender e explicar a realidade, continuar aprendendo e colaborar para a construção de uma sociedade justa, democrática e inclusiva” (BRASIL, 2018, p. 9).

É nesse contexto que situamos a necessidade da ACT. Shen (1975) defende uma visão crítica sobre as ações da ciência e da tecnologia na sociedade, além de um olhar peculiar sobre as implicações dessas ações. Por sua vez, Chassot (2003) concebe a ACT como uma linguagem, ou seja, a capacidade das pessoas em interpretar o mundo em que vivem.

\footnotetext{
${ }^{1} \mathrm{O}$ termo Alfabetização Científica e Tecnológica (ACT) é adotado por diferentes autores internacionais, como, por exemplo Aceve do, Alonso e Manassero-Mas (2003) e Alonso (2010), e por autores nacionais como Auler e Delizoicov (2001) e Lorenzetti, Siemsen e Oliveira (2017).
} 
Shen (1975) sugere, ainda, a necessidade de alfabetizar em ciências e em tecnologias grupos sociais para a compreensão de dilemas de natureza científica e tecnológica como uma das condições da sua atuação democrática, crítica e cidadã. Ele propõe três níveis de Alfabetização Científica (AC): a AC prática - relativa ao uso do conhecimento científico na resolução de problemas práticos do cotidiano; a AC cívica - referente à conscientização crítica e à formação política diante de questões científicas; e AC cultural - relacionada ao conhecimento sobre a natureza da ciência. Esses níveis de AC foram revistos por Lorenzetti, Siemsen e Oliveira (2017), quando esses autores adicionam a tecnologia à educação voltada à alfabetização científica.

Portanto, entendemos que a ACT está relacionada à compreensão das aplicações e implicações da ciência e da tecnologia na sociedade e ao posicionamento crítico diante delas, uma vez que diversas atividades científicas e tecnológicas estão relacionadas às consequências positivas ou negativas para o bem-estar social.

O nosso pressuposto, neste estudo, é o de que a abordagem de QSC no ensino de ciências, e mais especificamente no ensino de química, pode contribuir na ACT de estudantes. Isto porque as QSC envolvem questões sociais, ambientais, econômicas, políticas, éticas e morais relativas às implicações e aplicações dos conhecimentos científicos e tecnológicos na sociedade.

Nesta direção, conduzimos este estudo a partir das seguintes questões de pesquisa: quais os níveis de ACT que podem ser identificados em estudantes no desenvolvimento de uma intervenção didática com a abordagem de QSC e quais são as possibilidades e limitações desta intervenção didática para a emergência dos níveis de ACT identificados?

Buscando respostas para as respectivas questões de pesquisa, temos neste estudo os objetivos de identificar os níveis de ACT expressados por estudantes no desenvolvimento de uma intervenção didática com a abordagem de QSC e analisar possibilidades e limitações da intervenção didática desenvolvida na emergência dos níveis de ACT identificados.

\section{Níveis de alfabetização científica e tecnológica}

Segundo Shen (1995) e Lorenzetti, Siemsen e Oliveira (2017), a ACT prática refere-se à compreensão de relações entre conceitos científicos e tecnológicos e as atividades diárias e práticas do cidadão. Neste nível, o cidadão pode compreender fenômenos naturais, bem como entender o funcionamento de tecnologias digitais. Um exemplo do nível da ACT prática pode ser quando o 
indivíduo diferencia gordura cis e trans ${ }^{2}$ ou compreende o funcionamento da internet $\mathrm{Wi}-\mathrm{F} i^{3}$ em aparelhos tecnológicos.

Já a ACT cívica é relativa ao desenvolvimento do pensamento crítico do cidadão, de modo a torná-lo apto a participar de decisões democráticas da sociedade que envolvem questões científicas e tecnológicas (SHEN, 1975; LORENZETTI; SIEMSEN; OLIVEIRA, 2017). Um exemplo do nível de ACT cívica pode ser quando o indivíduo entende que os produtos de limpeza têm sua funcionalidade, mas podem gerar resíduos contaminantes e interferir no ecossistema marinho, caso esses resíduos não sejam tratados. Em outras palavras, a ACT cívica proporciona ao cidadão a formulação de ideias críticas para compreensão e posicionamento diante de aplicações e implicações da ciência e da tecnologia na sociedade.

Por último, a ACT cultural converge para a compreensão da natureza da ciência e da tecnologia e da relação destas com a cultura humana. Neste nível, o sujeito tem condições de perceber a interferência da ciência e da tecnologia no desenvolvimento humano (ACEVEDO; ALONSO; MANASSERO-MAS, 2003). Adicionalmente, este nível pode contribuir para desmistificar superstições e crenças acerca da ciência e da tecnologia (LORENZETTI; SIEMSEN; OLIVEIRA, 2017; SHEN, 1975), como, por exemplo, a crença da neutralidade científica.

Em síntese, podemos dizer que a ACT, em seus diferentes níveis, subsidia as seguintes ações: a tomada de decisão e a capacidade em analisar, sintetizar e avaliar informações; o raciocínio lógico; o saber julgar fatos sobre relações entre a ciência, a tecnologia e a sociedade, bem como suas consequências; e o lidar com questões éticas, diferenciando caminhos positivos e negativos da ciência e tecnologia com as relações socioambientais (ZEIDLER; NICHOLS, 2009).

\section{Questões sociocientíficas no ensino de química}

Conrado e Nunes-Neto (2018) discutem a inserção de temas que versam as inferências e aplicações da ciência e da tecnologia na sociedade. Assim, debatem a introdução das Questões Sociocientíficas (QSC) no ensino de ciências.

Segundo esses autores, QSC são temáticas polêmicas, atuais e bastante divulgadas pelos veículos de comunicação. São dilemas que envolvem conhecimentos científicos e tecnológicos, mas vão além desses, visto que envolvem aspectos políticos, econômicos, morais, éticos, culturais, históricos, ambientais e de juízo (SANTOS; MORTIMER, 2009; SILVA; SANTOS, 2014).

\footnotetext{
2 Tipos de lipídeos, em que as gorduras - estado sólido - são ácidos graxos, formados majoritariamente por triglicerídeos; esses ácidos graxos apresentam insaturações que refletem na sua configuração geométrica, ocasionando dois isômeros espaciais: cis e trans (MERÇON, 2010).

${ }^{3}$ Protocolo de rede sem fio comumente utilizado para conectar redes locais de dispositivos e acesso à internet, como locais públicos

fornecendo esse acesso aos mais diversos dispositivos (tablets, smartphones, smart TVs, etc.).
} 
Nesta perspectiva, uma QSC permite uma abordagem multidisciplinar e eleva a capacidade de tomada de decisão e posicionamento crítico de estudantes diante de temáticas que envolvem ciência, tecnologia e sociedade, como, por exemplo, transexualidade, identidade e gênero; capitalismo, consumo e sustentabilidade; agrotóxicos; clonagem; aborto; doação de órgãos; desastres ambientais - mineração e rompimento de barragens, entre outras (CONRADO; NUNES-NETO, 2018; RATCLIFFE; GRACE, 2003; ZEIDLER; NICHOLS, 2009).

A abordagem de QSC em aulas de ciências propicia, entre outros aspectos, a contextualização do conhecimento científico, a aproximação de estudantes a situações reais, a distinção sobre fatos, argumentos e opiniões, questões voltadas à linguagem (HODSON, 2018); além de favorecer a compreensão de fatores políticos, socioculturais, religiosos e econômicos, quando relacionados às pesquisas e produtos científicos e tecnológicos (KOLSTO, 2004). Complementarmente, as QSC emergem de conteúdos problematizados culturalmente, realçando o processo constante de reflexão sobre o papel social das ciências e tecnologias (SANTOS; MORTIMER, 2009).

Adicionalmente, as QSC, sendo temáticas complexas e controversas, possuem características: estimulam discussões interdisciplinares; explicitam pressuposições éticas e ambientais; envolvem discussões de valores morais, interesses e opiniões; possibilitam tomadas de decisão e ação; envolvem formação de opiniões, para escolhas pessoais e sociais; estão relacionadas às transições da vida social; envolvem reconhecimento e avaliação de informações incompletas e se essas são locais, nacionais e/ou internacionais; proporcionam reflexão crítica sobre as relações entre ciência, tecnologia e a sociedade (CONRADO; NUNES-NETO, 2018; HODSON, 2018; RATCLIFFE; GRACE, 2003; SANTOS; MORTIMER, 2009; ZEIDLER; NICHOLS, 2009).

Reforçamos que o propósito das QSC é guiar estudantes a avaliarem quais valores sociais, políticos, econômicos, éticos e morais, por exemplo, orientam o desenvolvimento histórico e de determinados grupos sociais. Além disso, "perguntar o que pode e deve ser alterado, a fim de alcançar democracias socialmente mais justas e assegurar estilos de vida ambientalmente mais sustentáveis" (HODSON, 2018, p. 34).

Conrado e Nunes-Neto (2018) e Ratcliffe e Grace (2003) defendem que a abordagem de QSC pode lançar mão do uso de casos, histórias ou estórias. Para eles, o caso possibilita a exploração dos aspectos das QSC abordadas. Adicionalmente, esses autores destacam que o estudo de caso valoriza habilidades, competências e questões éticas, visto que pode conduzir estudantes à valorização de ideias democráticas e ao exercício de tomada de decisão, instigando-os a se posicionarem sobre as características multidisciplinares diversas nele abordadas. 
Para as autoras Sá, Francisco e Queiroz (2007), o uso de casos no ensino de ciências corrobora o processo de autonomia dos estudantes, pois esses estarão diante de problemas e deverão posicionar-se sobre tais problemas. Essas autoras enfatizam que o estudo de caso pode desenvolver "[...] habilidades de pensamento crítico de ordem superior dos alunos" (SÁ; FRANCISCO; QUEIROZ, 2007, p. 732). Por essa razão, consideramos que o uso de casos pode auxiliar na abordagem e desenvolvimento de QSC.

Além do uso de casos, Conrado e Nunes-Neto (2018) propõem o uso de questões norteadoras, as quais são orientações para que estudantes desenvolvam posicionamento crítico sobre os principais problemas envolvidos no caso. A partir das questões norteadoras, é possível perceber diferentes complexidades e múltiplas perspectivas, desenvolver argumentos sobre o caso e/ou sobre a QSC, compreender teorias e conceitos científicos e investigar técnicas e tecnologias relacionadas à QSC, entender consequências e influências relativas à QSC na sociedade, emitir juízos sobre atores sociais e sobre consequências socioambientais relativas às diferentes decisões desses atores sociais (CONRADO; NUNES-NETO, 2018).

Portanto, considerando as especificidades da abordagem de QSC, refletimos que essa pode contribuir para a emergência da ACT de estudantes em seus diferentes níveis e, ao mesmo tempo, para o exercício da cidadania e promoção da educação científica (RATCLIFFE; GRACE, 2003).

\section{Desenvolvimento teórico-metodológico da pesquisa}

Neste estudo, seguimos algumas características da pesquisa qualitativa, visto que neste tipo de pesquisa:

\footnotetext{
Preocupa-se muito mais com o processo do que com o produto. Na análise dos dados coletados, não há preocupação em comprovar hipóteses previamente estabelecidas, porém estas não eliminam a existência de um quadro teórico que direcione a coleta, a análise e a interpretação dos dados [...] (PRODANOV; FREITAS, 2013, p. 70).
}

Contamos com a participação de trinta estudantes de uma turma da $2^{\mathrm{a}}$ série do Ensino Médio, com faixa etária entre 14 e 19 anos, de uma escola pública estadual da Região Metropolitana do Recife, Pernambuco. Por questões éticas, preservamos os nomes dos estudantes, os quais foram identificados pela numeração de 1 a 30, ou seja, identificamos os estudantes por A1 a A30. Desse modo, seguimos três etapas metodológicas para o desenvolvimento deste estudo: planejamento da intervenção didática a partir da abordagem de QSC (etapa 1); desenvolvimento da intervenção didática planejada (etapa 2); coleta e análise dos dados (etapa 3). 
Para o planejamento da intervenção didática (primeira etapa metodológica deste estudo), optamos pela QSC “Desastres ambientais: derramamento de óleo no litoral do nordeste”. Essa QSC está relacionada ao acidente socioambiental que ocorreu em agosto de 2019, relativo à presença de óleo bruto (petróleo) em todo litoral da região nordeste e em algumas praias do Sudeste. Este acidente é polêmico, pois envolve diversas opiniões, e foi divulgado nos veículos de comunicação (TVs, jornais impressos, sites de notícias) ${ }^{4}$ locais, nacionais e internacionais, além de envolver questões científicas e tecnológicas, ou seja, é uma temática que apresenta características de uma QSC (CONRADO; NUNES-NETO, 2018). Nos noticiários, várias especulações foram apresentadas, como, por exemplo, afundamentos de navios, derramamento acidental ou proposital durante manobra ou trânsito de navios petroleiros e o descarte irregular do óleo. Entretanto, o que se sabe é que inúmeras famílias foram afetadas e que os órgãos competentes disponibilizaram EPI’s e pessoal qualificado, para a retirada do óleo, quase dois meses após o surgimento das primeiras manchas dessa substância. Até o momento, ninguém foi penalizado por este crime.

Após a escolha da QSC, seguimos o planejamento com a elaboração de um caso e das questões norteadoras, conforme orientam Conrado e Nunes-Neto (2018). Elaboramos o caso intitulado "Óleo pesado que boia" e as questões norteadoras - instrumentos de coleta de dados, apresentadas no quadro 1.

Quadro 1 - Questões norteadoras relativas ao caso

\begin{tabular}{|c|c|}
\hline $\begin{array}{l}\mathbf{N}^{\circ} \text { da } \\
\text { questão }\end{array}$ & Questão \\
\hline 1 & Qual(ais) o(s) assunto(s) abordado no caso? \\
\hline 2 & $\begin{array}{c}\text { O que é densidade e como essa grandeza física está relacionada com o } \\
\text { surgimento das manchas de óleo no litoral de Pernambuco e em outros estados } \\
\text { do nordeste? }\end{array}$ \\
\hline 3 & Há diferenças quando o óleo é adicionado em água doce? \\
\hline 4 & $\begin{array}{l}\text { Quais os aspectos relacionados a um desastre ambiental como o derramamento } \\
\text { de óleo (petróleo) em alto mar? }\end{array}$ \\
\hline 5 & $\begin{array}{c}\text { Qual a importância do petróleo no desenvolvimento social? Podemos nos } \\
\text { desenvolver sem esse material? }\end{array}$ \\
\hline
\end{tabular}

Fonte: Autores (2021).

O desenvolvimento da intervenção didática (segunda etapa metodológica) foi ministrado por um dos autores desse estudo, o qual denominamos de professor-pesquisador, e ocorreu em dois encontros, contemplando duas aulas geminadas de cem minutos em cada um deles. No primeiro encontro, o professor-pesquisador discutiu com estudantes sobre o que é uma QSC e, em

\footnotetext{
${ }^{4}$ Disponível em: https://www.camara.leg.br/noticias/768374-debate-avalia-derramamento-de-oleo-no-nordeste-que-vai-completar-dois-anossem-respostas-acompanhe. Acesso em: 10 ago. 2021.
} 
seguida, apresentou alguns exemplos de temas que podem ser considerados como QSC, tais como aborto, legalização da maconha para uso medicinal, transexualidade e uso de terras indígenas e quilombolas para produção agrícola. Posteriormente, o professor-pesquisador iniciou um debate com os estudantes sobre temas que poderiam ser abordados nas aulas de química e que estivessem sendo divulgados, nos últimos dias, em veículos de comunicação. Alguns estudantes citaram como um dos temas o surgimento de óleo nas praias de Pernambuco. Após essa discussão, o professorpesquisador entregou aos estudantes o caso impresso para leitura individual.

Após a leitura, os estudantes foram organizados em semicírculo para o debate sobre o caso. Em seguida, o professor-pesquisador iniciou a discussão sobre os conteúdos de densidade e solubilidade e a QSC em tela. Os estudantes foram orientados a responder as questões norteadoras um, dois e três. Para isso, eles contaram com, aproximadamente, trinta minutos. Após esse período, foi retomada a atenção dos estudantes para as considerações finais com as relações do conteúdo densidade e solubilidade e a QSC. Portanto, neste primeiro encontro, foram discutidos com os estudantes aspectos políticos, econômicos, sociais, éticos e ambientais, além dos científicos, relativos ao caso e a QSC.

Já no segundo encontro, o professor-pesquisador retomou com os estudantes os aspectos discutidos anteriormente e, em seguida, conduziu outras discussões sobre o caso em seus aspectos científicos, tecnológicos, ambientais, éticos e sociais. Após as discussões sobre a QSC, relativas aos aspectos tecnológicos e científicos, os estudantes retornaram a responder as questões norteadoras quatro e cinco, relativas ao caso e, principalmente, aos aspectos tecnológicos e sociais da QSC. Após trinta minutos, depois de responderam as respectivas questões, foram orientados a entregar as respostas das questões norteadoras. Em seguida, iniciou-se os debates finais sobre a QSC e os conteúdos científicos densidade e destilação fracionada.

Para auxiliar os estudantes nas proposições de soluções para o caso, o professorpesquisador ministrou uma aula expositiva dialogada sobre aspectos políticos, econômicos, sociais, éticos, ambientais e tecnológicos envolvidos na QSC e no caso, com vistas a promover o desenvolvimento de posicionamento crítico sobre tais aspectos. A próxima etapa da intervenção didática seria a discussão no grande grupo sobre as respostas às questões norteadoras e às soluções para o caso, entretanto, esta etapa não foi realizada, visto que os estudantes teriam que participar de uma gincana escolar e realizar outras atividades avaliativas de acordo com o calendário da escola.

Para a etapa de coleta e análise dos dados (terceira etapa metodológica deste estudo), consideramos as respostas dos estudantes às questões norteadoras sobre o caso, com os objetivos de identificarmos os níveis de ACT expressados pelos estudantes e analisarmos contribuições da 
intervenção didática com a abordagem da QSC "Desastres ambientais: derramamento de óleo no litoral do nordeste" para a emergência dos níveis de ACT identificados. Desta forma, consideramos as seguintes categorias analíticas, conforme quadro 2 :

Quadro 2 - Descrição das categorias analíticas

\begin{tabular}{|c|c|}
\hline Categorias & Descrição \\
\hline ACT prática & $\begin{array}{r}\text { Compreende e usa conhecimentos e linguagens científicos e tecnológicos na } \\
\text { resolução de problemas do cotidiano }\end{array}$ \\
\hline ACT cívica & $\begin{array}{r}\text { Compreende aspectos sociais relativos à ciência e à tecnologia e desenvolve } \\
\text { pensamento crítico para participação nas decisões democráticas }\end{array}$ \\
\hline ACT cultural & Compreende questões sobre a Natureza da Ciência e da Tecnologia \\
\hline
\end{tabular}

Fonte: Autores (2021).

\section{Resultados e discussão}

Inicialmente, analisamos as respostas dos estudantes para as questões norteadoras relativas ao caso "Óleo pesado que boia" para identificarmos os níveis de ACT expressados por eles. Posteriormente, analisamos (no segundo momento analítico) possibilidades e limitações da intervenção didática com a abordagem da QSC "Desastres ambientais: derramamento de óleo no litoral do nordeste" para emergências dos níveis de ACT identificados.

Neste sentido, sobre a primeira questão norteadora, "Qual(ais) o(s) assunto(s) abordado(s) no caso?", transcrevemos as respostas de A1 e A8:

\footnotetext{
A1: "É de desastre ambiental. Onde a vida marinha está sendo prejudicada pelo óleo. Temos também a economia, pescadores estão sofrendo com esse acontecimento. Além desses aspectos, tem a parte da política e tecnologia. Isto está relacionado as manchas de óleo que estão causando enorme problemas no litoral do nordeste, esse petróleo é uma mistura complexa formada por muitos materiais orgânicos, que não são solúveis em água. Onde a densidade e temperatura estão envolvidos nessa mistura".

A8: "O óleo que está no mar, junto com uma das consequências, que é o fato dos pescadores não terem o que pescar, porque os peixes estão se escondendo do óleo ou estão contaminados".
}

Percebemos que A1 e A8 apontaram em suas respostas diferentes assuntos envolvidos no caso, como, por exemplo, aqueles relativos ao acidente, ao prejuízo à vida marinha, aos prejuízos econômicos dos pescadores e ao petróleo e sua propriedade de ser insolúvel em água.

Quanto à segunda questão norteadora, "O que é densidade e como essa grandeza física está relacionada com o surgimento das manchas de óleo no litoral de Pernambuco e em outros estados do nordeste?", transcrevemos as respostas de A24 e A21: 
A24: "Essas manchas de óleo não conseguem se diluir na água doce ou salgada, por conta de seus materiais orgânicos".

A21: "Densidade é a massa sobre o volume. Através dela podemos saber de onde é o petróleo, o que ele pode causar ao entrar em contato com a pele, é através da densidade que podemos ver o óleo sobre a água, exatamente porque a densidade do óleo é menor".

Considerando as respostas transcritas, percebemos que A24, embora não tenha definido o que é densidade, apontou outro aspecto científico relacionado ao caso - a solubilidade, mais especificamente, a insolubilidade do óleo em água. A21, por sua vez, faz uma relação entre o conceito de densidade e o surgimento do petróleo nas praias, acrescentando que a densidade está relacionada ao tipo de petróleo e, por meio dela, pode-se saber a sua origem.

Para a terceira questão norteadora, "Há diferenças quando o óleo é adicionado em águas doces?”, transcrevemos as respostas de A30:

\begin{abstract}
A30: “Quando o óleo é adicionado à água salgada ele boia e não se mistura. Quando é adicionado à água doce o óleo vai para o fundo e causa vários problemas, não só para o meio ambiente, mas também para os peixes e para as pessoas, porque os peixes vão se alimentar desse óleo e com isso vai prejudicar mais pessoas".
\end{abstract}

Entendemos que A30 traz uma resposta esperada para a questão, ao considerar a propriedade densidade e problemas específicos socioambientais propostos pela QSC em tela.

Quanto à quarta questão, “Quais os aspectos relacionados a um desastre ambiental como o derramamento de óleo (petróleo) em alto mar?", destacamos as respostas de A15, A19, A21 e A22:

\footnotetext{
A15: "São os que dependem da pesca e de outros recursos marinhos, e os peixes também são prejudicados pelo óleo".

A19: "Aspectos econômicos: os pescadores que precisam da pesca para sobreviver estão sendo atingidos diretamente com a questão financeira, pois muitas pessoas estão assustadas e por isso não consumem crustáceo, que é o meio de sobrevivência de muitos. Aspectos sociais e éticos: é toda uma sociedade atingida, de várias formas, tanto pescadores quanto consumidores, e também temos a atitude das pessoas a fazer a limpeza dos mares, voluntariamente".

A21: "Éticos: as pessoas que se comoveram para ajudar a retirar o óleo e nem pensou na saúde. Poluição: mesmo retirando todo o óleo ainda vai ficar poluído. Políticos: a demora para distribuição de EPI's".

A22: "Político: demora para tomar providências. Econômico: prejudica o turismo, consumo de peixes, pescadores, supermercados".
}

A partir das respostas de A15, A19, A21 e A22, observamos que A15 sinalizou implicitamente aspectos econômicos e ambientais e A19, A21 e A22 apontaram explicitamente diversos aspectos, tais como, econômicos, sociais, éticos e políticos.

Para a quinta questão, "Qual a importância do petróleo no desenvolvimento social? Podemos nos desenvolver sem esse material?", destacamos a resposta de A5: 
A5: “O petróleo é importante porque através dele são extraídos a gasolina, o óleo diesel o álcool, que é muito importante para o desenvolvimento social”.

Nas respostas de A5, podemos perceber que o estudante destaca a importância do petróleo para o desenvolvimento social.

A partir das respostas de A1, A5, A8, A15, A19, A21, A22, A24 e A30, pudemos identificar níveis de ACT expressados por eles. Assim, identificamos o nível de ACT prática, relativo à compreensão de relações entre conceitos científicos e tecnológicos e as atividades diárias e práticas do cidadão (LORENZETTI; SIEMSEN; OLIVEIRA, 2017; SHEN, 1975), quando: A21 respondeu "[...] é através da densidade que podemos ver o óleo sobre a água, exatamente porque a densidade do óleo é menor"; A2 respondeu "Essas manchas de óleo não conseguem se diluir na água doce ou salgada, por conta de seus materiais orgânicos"; e A30 respondeu "Quando o óleo é adicionado à água salgada ele boia e não se mistura [...]”.

Identificamos o nível de ACT cívica, relativo ao desenvolvimento do pensamento crítico do cidadão, de modo a torná-lo apto a participar nas decisões democráticas da sociedade, relativas às questões científicas e tecnológicas (LORENZETTT, SIEMSEN; OLIVEIRA, 2017; SHEN, 1975), quando os estudantes se posicionam criticamente diante das consequências do derramamento do óleo nas praias. Destacamos evidências deste nível de ACT na resposta de A19, ao responder que esse acidente envolve aspectos econômicos e políticos considerando, por exemplo, que "[...] os pescadores que precisam da pesca para sobreviver estão sendo atingidos diretamente com a questão financeira [...]".

Quanto ao nível da ACT cultural, relativo ao entendimento da interferência da ciência e da tecnologia no desenvolvimento humano (ACEVEDO; ALONSO; MANASSERO-MAS, 2003; LORENZETTI, SIEMSEN; OLIVEIRA, 2017; SHEN, 1975), destacamos que A5, ao responder que "O petróleo é importante porque através dele são extraídos a gasolina, o óleo diesel o álcool, que é muito importante para o desenvolvimento social", traz em sua resposta indícios de uma compreensão da interferência da ciência e da tecnologia no desenvolvimento social.

Continuando as análises, ainda no segundo momento analítico, buscamos compreender quais foram as possibilidades e as limitações da intervenção didática segundo a abordagem da QSC em tela para o desenvolvimento dos níveis de ACT identificados.

Quanto à primeira possibilidade, corroboramos a ideia de que a abordagem de QSC proporciona a "compreensão de teorias e conceitos científicos e tecnológicos relacionados à QSC" (CONRADO; NUNES-NETO, 2018, p. 90) e destacamos que a intervenção didática de abordagem da QSC aqui discutida contribuiu para a emergência do nível de ACT prática (SHEN, 
1975; LORENZETTTI, SIEMSEN; OLIVEIRA, 2017) pelos estudantes. Evidências dessa contribuição podem ser identificadas quando os estudantes A21 e A24, por exemplo, responderam à segunda questão norteadora sinalizando que eles compreenderam relações entre conceitos científicos de densidade e de solubilidade e o aparecimento do petróleo nas praias.

Outra possibilidade que identificamos refere-se ao fato de que a abordagem de QSC oportuniza a compreensão de fatores políticos, socioculturais, religiosos e econômicos relacionados à ciência e à tecnologia, conforme destacado por Kolsto (2004) e Conrado e NunesNeto (2018). Dessa forma, podemos dizer que a intervenção didática de abordagem da QSC discutida contribuiu para a emergência do nível de ACT cívica (SHEN, 1975; LORENZETTI, SIEMSEN; OLIVEIRA, 2017) dos estudantes. Evidências dessa contribuição são identificadas quando os estudantes A15, A19, A21 e A22 respondem à terceira questão norteadora, por exemplo, colocando-se criticamente a respeito das implicações econômicas, sociais, éticas e políticas envolvidas no derramamento de óleo no litoral do nordeste.

A próxima possibilidade identificada volta-se ao fato de que a abordagem de QSC envolve discussão sobre aplicações e inferências da ciência e tecnologia na sociedade (CONRADO; NUNES-NETO, 2018) e, portanto, destacamos que a intervenção didática de abordagem da QSC discutida contribuiu para a emergência do nível de ACT cultural (SHEN, 1975; LORENZETTI; SIEMSEN; OLIVEIRA, 2017) pelos estudantes. Neste sentido, podemos dizer que A5 trouxe evidências, em sua resposta à quinta questão norteadora, que compreende o petróleo como matéria-prima para diversos produtos, como gasolina, óleo diesel e álcool, e que estes contribuem para o desenvolvimento social. Contudo, A5 não trouxe em sua resposta elementos que sinalizem o petróleo enquanto produto que contribui para o desenvolvimento social, assim como pode trazer interferências negativas para a sociedade do ponto de vista ambiental, por exemplo. Ainda precisamos ressaltar que o álcool não é produto da extração do petróleo. O álcool é obtido a partir da cana de açúcar ou de cereais (como milho e arroz) (MORTIMER; MACHADO, 2013).

Ainda como possibilidades para a emergência dos níveis de ACT dos estudantes, destacamos que a QSC abordada na intervenção didática foi voltada à vivência dos estudantes (ZEIDLER; HERMAN; SADLER, 2019), propiciou a aproximação dos estudantes a situações reais; promoveu discussões em múltiplas perspectivas, oportunizou a compreensão de conceitos científicos e oportunizou a identificação de aspectos políticos, econômicos, ambientais, sociais, além de científicos e tecnológicos (CONRADO; NUNES-NETO, 2018).

Como limitações da intervenção didática de abordagem da QSC aqui apresentada para a ACT dos estudantes, podemos destacar a ausência de discussões acerca de valores morais, de 
interesses e de opiniões (CONRADO; NUNES-NETO, 2018; SILVA; SANTOS, 2014), importantes no processo de formação crítica frente às ações da ciência e da tecnologia na sociedade e de atuação reflexiva e emancipada dessas relações, além da oportunidade de os estudantes expressarem juízos sobre as diferentes decisões de atores sociais (RATCLIFFE; GRACE, 2003; SILVA; SANTOS, 2014), quando estes emitem e compreendem a não neutralidade da ciência no processo formativo de uma determinada sociedade, por exemplo. Portanto, a ausência de discussão sobre tais aspectos pode ter implicado nas limitações para a ACT, em sua totalidade, de estudantes, em especial para a ACT cívica e a ACT cultural.

\section{Considerações finais}

Neste trabalho, tivemos como objetivos identificar os níveis de Alfabetização Científica e Tecnológica expressados por estudantes no desenvolvimento de uma intervenção didática com a abordagem de Questão Sociocientífica, além de analisar possibilidades e limitações da intervenção didática desenvolvida na emergência dos níveis de ACT identificados.

Foram identificados entre os estudantes participantes os três níveis de ACT: o da ACT prática, o da ACT cívica e o da ACT cultural. Ademais, por meio do desenvolvimento da intervenção didática: 1) estudantes compreenderam relações entre conceitos científicos (densidade e solubilidade) e situações reais (aparecimento do petróleo nas praias), evidenciando o nível de ACT prática; 2) estudantes expressaram-se criticamente diante das consequências (econômicas, sociais, éticas e políticas) do derramamento de petróleo nas praias, evidenciando o nível de ACT cívica; 3) estudantes compreenderam relações entre desenvolvimento científico e tecnológico e o desenvolvimento social, entretanto, com ênfase maior nas aplicações do que nas interferências negativas de atividades científicas e tecnológicas na sociedade.

Quanto às possibilidades da intervenção didática desenvolvida na emergência dos níveis de ACT identificados, destacamos os seguintes pontos: a compreensão de relações entre conceitos científicos de densidade e de solubilidade e o aparecimento do petróleo nas praias, refletindo no nível de ACT prática; a compreensão de implicações econômicas, sociais, éticas e políticas envolvidas no derramamento de óleo no litoral do nordeste, refletindo no nível de ACT cívica; a compreensão pelos estudantes de que o petróleo é matéria-prima para diversos produtos, como gasolina e óleo diesel, por exemplo, e de que estes combustíveis contribuem para o desenvolvimento social, refletindo no nível de ACT cultural.

Outras possibilidades podem ter sido propiciadas pela intervenção didática com a abordagem da QSC "Desastres ambientais: derramamento de óleo no litoral do nordeste", como, 
por exemplo, aproximação dos estudantes a situações reais, discussões em múltiplas perspectivas, compreensão de conceitos científicos e a abordagem de aspectos políticos, econômicos, ambientais, sociais, além de científicos e tecnológicos.

Entre as limitações da intervenção didática desenvolvida na emergência dos níveis de ACT identificados, destacamos a ausência de discussão sobre valores, interesses e opiniões pessoais dos estudantes que pode ter limitado a emergência dos níveis da ACT cívica e da ACT cultural.

Em tempo, enfatizamos que a abordagem de QSC pode se constituir como estratégia didática para o alcance da ACT de estudantes, um dos objetivos atuais para a educação em ciências. Entretanto, parece relevante considerar o atendimento aos seus diferentes níveis de ACT. E, nesta perspectiva, esse aspecto pode refletir em novas questões de pesquisa, como, por exemplo, quais as atividades devem ser realizadas em uma intervenção didática com abordagem de QSC para o desenvolvimento dos três níveis de ACT pelos estudantes?

\section{Referências}

ACEVEDO, J. A. D.; ALONSO, A. V.; MANASSERO-MAS, M. A. Papel de la educación CTS en una alfabetización científica y tecnológica para todas las personas. Revista Electrónica de Enseñanza de las Ciencias, Madrid, v. 02, n. 02, p. 80-111, 2003.

ALONSO, A. V. Importância da alfabetização científica e do conhecimento acerca da natureza da Ciência e da Tecnologia para a formação do cidadão. In: MACIEL, M. D.; AMARAL, C. L. C.; GUAZELLI, I. R. B (Orgs.). Ciencia, tecnología e sociedade: pesquisa e ensino. São Paulo: Terracota, 2010.

ALMEIDA, M. T.; GUIMARÃES, M. A. Raciocínio moral em questões sociocientíficas: argumentação de licenciandos de ciências sobre eutanásia. Amą̧ônia: revista de educação em ciências e matemática. v. 15, n. 34, p. 80-95. jul./dez. 2019.

AULER, D.; DELIZOICOV, D. Alfabetização científico-tecnológico para quê?. Revista Ensaio, Belo Horizonte, v. 03, n. 02, p. 122-134, 2001.

BRASIL. Lei n 9.394, de 20 de dezembro de 1996. Estabelece as diretrizes e bases da educação nacional. Diário Oficial da União: seção 1, Brasília, DF, ano 134, n. 248, p. 1-27, 23 dez. 1996. PL $1258 / 1988$

BRASIL. Base Nacional Comum Curricular. Brasília: MEC, 2018. Disponível em: http://basenacionalcomum.mec.gov.br/a-base. Acesso em: 10 ago. 2021.

BOCHECO, Otávio. Parâmetros para a abordagem de evento no enfoque CTS. 2011. Dissertação (Mestrado em Educação Científica e Tecnológica) - Centro de Ciências da Educação, Universidade Federal de Santa Catarina, Florianópolis, 2011. 
CHASSOT, A. Alfabetização cientifica: uma possibilidade para inclusão social. Revista Brasileira de Educação, n. 22, p. 89-100, 2003.

CONRADO, D. M.; NUNES-NETO, N. Questões sociocientíficas: fundamentos, propostas de ensino e perspectivas para ações sociopolíticas. 1. ed. Salvador: EDUFBA, p. 27-57, 2018.

GENOVESE, C. L. C. R.; GENOVESE, L. G. R.; CARVALHO, W. L. P. Questões sociocientíficas: origem, características, perspectivas e possibilidades de implementação no ensino de ciências a partir dos anos iniciais do Ensino Fundamental. Amaz̧ônia: revista de educação em ciências e matemática. v. 15, n. 34, p. 5-17. jul./dez. 2019.

HODSON, D. Realçando o papel da ética e da política na educação científica: algumas considerações teóricas e práticas sobre questões sociocientíficas. In: CONRADO, D. M.; NUNES-NETO, N. (org.). Questões sociocientíficas: fundamentos, propostas de ensino e perspectivas para ações sociopolíticas. 1. ed. Salvador: EDUFBA, 2018.

KOLSTO, S. D. Scientific literacy for citizenship: Tools for dealing with the science dimension of controversial socioscientific issues. Science Education. v. 85 (3), p. 291-310, 2004.

LORENZETTI, L.; SIEMSEN, G. H.; OLIVEIRA, S. Parâmetros de Alfabetização Científica e Alfabetização Tecnológica na Educação em Química: analisando a temática ácidos e bases. ACTIO, Curitiba v. 2, n. 1, p. 4-22, jan./jun. 2017.

MERÇON, F. O que é uma gordura trans. Química Nova na Escola, v. 32, n. 2, p. 78-83, 2010.

MORTIMER, E. F.; MACHADO, A. H. Quimica. 3. ed. v. 3. São Paulo: Scipione, 2013.

PÉREZ, L. F. M. Questões sociocientificas na prática docente: ideologias, autonomia e formação de professores. São Paulo. Editora Unesp, 2012.

PRODANOV, C. C.; FREITAS, E. C. de. Metodologia do trabalho cientifico: métodos e técnicas da pesquisa e do trabalho acadêmico. 2. ed. Novo Hamburgo: Feevale, 2013.

RATCLIFFE, M.; GRACE, M. Science education for citizenship: teaching Socio-scientific issues. 1. ed. Philadelphia. Maidenhead: Open University Press, 2003.

SÁ, L. P.; FRANCISCO, C. A.; QUEIROZ, S. L. Estudos de caso em química. Química Nova, v. 30, n. 3, p. 731-739, 2007.

SADLER, T. D. Informal reasoning regarding socioscientific issues: a critical review of research. Journal of Research in Science Teaching, v. 41, n. 5, p. 513-536, 2004.

SANTOS, W. L. P.; MORTIMER, E. F. Abordagem de aspectos sociocientíficos em aulas de ciências: possibilidades e limitações. Investigações em Ensino de Ciências, v.14, n. 2, p. 191-218, 2009.

SHEN, B. S. P. Science Literacy: Public understanding of science is becoming vitally needed in developing and industrialized countries alike. American Scientist. v. 16, n. 03, p. 265-268, 1975.

SILVA, S. M. B.; SANTOS, W. L. P. Questões sociocientíficas e o lugar da moral nas pesquisas em ensino de ciências. Interações, n. 31, p. 124-148, 2014. 
ZEIDLER, D. L.; NICHOLS, B. H. Socioscientific issues: theory and practice. Journal of Elementary Science Education, v. 21, n. 2, p. 49-58, 2009.

ZEIDLER, D. L.; HERMAN, B. C.; SADLER, T. D. New orientations in socioscientific issues research. Disciplinary and Interdisciplinary Science Education Research. v. 1, n. 11, p. 1-9, 2019. 